\title{
Toxicity assessment of crude and partially purified extracts of marine Synechocystis and Synechococcus cyanobacterial strains in marine invertebrates
}

\author{
Rosário Martins $^{\mathrm{a}, \mathrm{b}, \mathrm{c}}$, Nuria Fernandez ${ }^{\mathrm{d}}$, Ricardo Beiras ${ }^{\mathrm{d}}$, Vitor Vasconcelos ${ }^{\mathrm{a}, \mathrm{b}}$ \\ ${ }^{a}$ Departamento de Zoologia e Antropologia, Faculdade de Ciências da Universidade do Porto Praça Gomes Teixeira, 4009-002 Porto, \\ Portugal \\ ${ }^{b}$ Laboratório de Ecotoxicologia Dr. Augusto Nobre, Centro Interdisciplinar de Investigação Marinha e Ambiental, Rua dos Bragas \\ 289, 4050-123 Porto, Portugal
}

${ }^{c}$ Escola Superior de Tecnologia da Saúde do Porto, Rua João de Oliveira Ramos, 87 4000-294 Porto, Portugal

d Laboratório de Ecoloxía e Bioloxía Animal, Facultade de Ciencias, Universidade de Vigo, E-36200 Vigo, Galicia, Spain

\begin{abstract}
Among the Cyanoprokaryota, the genera Synechocystis and Synechococcus have rarely been studied with respect to potential toxicity. This is particularly true with marine environments where studies about the toxicity of cyanobacteria are restricted to filamentous forms at the warmer temperate and tropical regions and also to filamentous forms at cold seas such as the Baltic Sea. In this study, we describe the effects of cyanobacterial strains of the Synechocystis and Synechococcus genera isolated from the marine coast of Portugal, on marine invertebrates. Crude and partially purified extracts at a concentration of $100 \mathrm{mg} / \mathrm{ml}$ of freeze-dried material of the marine strains were tested for acute toxicity in nauplii of the brine shrimp Artemia salina, in the rotifer Brachionus plicatillis and in embryos of the sea urchin Paracentrotus lividus and the mussel Mytilus galloprovincialis. The cyanobacterial extracts, especially the crude extract, had an impact on A. salina nauplii. No significant toxic effects were registered against the rotifer. A negative impact of all strains was recorded on the embryonic development of the sea urchin, with toxic effects resulting in an inhibition of embryogenesis or development of smaller larvae. To the mussel embryos, the effects of cyanobacterial extracts resulted in a complete inhibition of embryogenesis. The results of all assays indicate that Synechocystis and Synechococcus marine strains contained toxic compounds to marine invertebrates.
\end{abstract}

\section{Keywords}

Cyanobacteria toxicity; Synechococcus; Synechocystis; Artemia salina; Brachionus plicatillis; Mytilus galloprovincialis; Paracentrotus lividus 


\section{Introduction}

Cyanobacteria have long been recognized as harmful to a wide range of organisms due to the potential production of toxic compounds. Hepatotoxins, neurotoxins, cytotoxins, dermatotoxins and irritant toxins were characterized from several cyanobacterial genera and species (Wiegand and Pflugmacher, 2005).

Worldwide intoxication of aquatic organisms involving cyanobacterial toxins are well documented in freshwater ecosystems (Codd et al., 2005). In contrast, cases of intoxications caused by marine cyanobacteria are rarer and more localized. Toxic episodes are mainly reported from cold water seas such as the Baltic Sea and from coastal tropical and subtropical regions, where the occurrence of cyanobacteria in large densities is frequent. Reports concerning cyanobacterial toxicity at marine environments are also restricted to some filamentous forms. In the Baltic Sea, blooms of Nodularia spumigena are a common issue during the summer months, as the production of the hepatotoxin nodularin is common ( Sivonen et al., 1989; Rantajärvi, 1998; Repka et al., 2004). In tropical and subtropical regions, cyanobacteria of the genera Trichodesmium ( Carpenter et al., 2004; Hawser et al., 1992; Negri et al., 2004) and Lyngbya (Albert et al., 2005; Watkinson et al., 2005) are the most common ones. A high variety of toxic chemicals were extracted from the species Lyngbya majuscula ( Osborne et al., 2001) and several animal deaths related to marine cyanobacterial blooms have also been reported ( Pittman and Pittman, 2005). Toxic effects caused by marine cyanobacteria have been described for different organisms such as rotifers ( Pushparaj et al., 1999), brine shrimp and prawns ( Hawser et al., 1992; Gerwick et al., 1994; Smith, 1996), molluscs ( Orjala and Gerwick, 1996; Negri et al., 2004) and fish ( Graber and Gerwick, 1998).

In the present study, marine Synechocystis and Synechococcus strains isolated from the Portuguese coast and maintained under laboratory conditions were investigated for the potential toxicity to marine invertebrates. The brine shrimp Artemia salina, the rotifer Brachionus plicatillis, the sea urchin Paracentrotus lividus and the mussel Mytilus galloprovincialis were the chosen species for the toxicity assays. These target species were chosen according to their ecological relevance and occurrence at the Portuguese coast. Brine shrimps and rotifers represent two of the main groups of pelagic invertebrates of marine coastal communities. These are major components of the zooplankton of coastal marine habitats, functioning as grazers on phytoplankton and as food for many invertebrates and fish larvae. The brine shrimp lethality assay is a standardized bioassay routinely used in marine research and aquatic toxicology for preliminary assessment of toxicity ( Solis et al, 1993). Regarding cyanobacteria, A. salina has been used to detect the toxicity of several species. Although the assay is rather inadequate regarding the elucidation of the mechanisms of action, it is very useful to assess the potential toxicity of strains. It was found that artemia nauplii mortality correlated well with concentrations of cyanobacterial toxins namely hepatotoxins ( Campbell et al., 1994) and neurotoxins ( Kiviranta et al., 1991). Regarding rotifers, the genus Brachionus has a cosmopolitan distribution and the species $B$. plicatillis is particularly common in brackish and marine environments. Toxicity tests using these organisms have been also used for the assessment of cyanobacterial toxicity ( Pushparaj et al., 1999; Maršálek and Bláha, 2004). Sea urchins and mussels are 
important benthic habitants of the littoral shores of coastal marine environments and the species $P$. lividus and M. galloprovincialis are especially common in the Portuguese coast. In the present study, we tested the effects of marine cyanobacterial extracts on the embryogenesis of these invertebrate species. Sea urchin and bivalve embryos have been recognized as valuable tools for toxicity assessment ( His et al., 1999; Beiras et al., 2003) and, as embryos and larvae are more sensitive to toxicants in general than adults of the same species, they represent critical life stages useful for toxicity assays ( Martin et al., 1981).

The potential negative effects of cyanobacteria on marine organisms can be particularly relevant in cases of bloom formation. In spite of the absence of records of marine cyanobacterial blooms in the Portuguese coast, the increase in nutrient enrichment due to human activities and consequently the increase on eutrophication and the rises in temperature due to the global warming, could enhance the possibility of harmful cyanobacterial bloom formation, as it has been registered in other parts of the world (Watkinson et al., 2005). Extensive spread of cyanobacteria may introduce important amounts of toxic bioactive secondary metabolites into the sea environments and therefore its toxicological risk for marine organisms should be assessed.

\section{Materials and methods}

\subsection{Cyanobacterial strains and cultivation}

Cyanobacterial strains were isolated from water samples collected near shore and from solid material such as rocks, shells and sand. Strains isolation and culture were performed in Z8 medium (Kotai, 1972) supplemented with $\mathrm{NaCl}$ at a concentration of $20 \mathrm{~g} / \mathrm{l}$. Strains were grown for 4 weeks in 41 medium, at $25^{\circ} \mathrm{C}$, light intensity of $10 \mu \mathrm{mol}$ photons/m s provided by cool white fluorescent tubes and with a light/dark cycle of $14 \mathrm{~h} / 10 \mathrm{~h}$. After the cultivation period, cells were harvested by centrifugation. Samples were frozen at $-20{ }^{\circ} \mathrm{C}$, freeze-dried and then stored at $-20{ }^{\circ} \mathrm{C}$. Twelve strains belonging to the genera Synechocystis and Synechococcus were tested for toxicity. Table 1 summarizes all the cyanobacterial strains used in the present work. All these strains were tested against the brine shrimp and the rotifer. Among these, ten strains were tested against the sea urchin embryogenesis ( Table 3) and two strains (LEANCYA 16 and 21) were tested against the mussel embryogenesis. 
Table 1.

Marine cyanobacterial strains tested for toxicological properties

\begin{tabular}{|c|c|}
\hline train designation & Species/genus \\
\hline EANCYA 1 & Synechocystis sp. \\
\hline EANCYA5 & Synechocystis sp. \\
\hline EANCYA 7 & Symechocaccus sp \\
\hline LEANCYA 10 & Symechocaccus sp \\
\hline LEANCYA 11 & Synechocaccus sp. \\
\hline EANCYA 13 & Synechocystis sp. \\
\hline LEANCYA 16 & Synechococcus sp \\
\hline LEANCYA 17 & Synechocystis sp. \\
\hline LEANCYA 18 & Synechocaccus sp. \\
\hline LEANCYA 19 & Synechococcus sp. \\
\hline LEANCYA 20 & Synechocystis sp. \\
\hline LEANCYA 21 & Synechocystis sp. \\
\hline
\end{tabular}

\subsection{Preparation of cyanobacterial extracts}

Extracts of each cyanobacterial strain were prepared by dissolving freeze-dried material in natural filtered $(0.2 \mu \mathrm{m}$ pore $)$ seawater, at a concentration of $100 \mathrm{mg} / \mathrm{ml}$. The solutions were homogenized by sonication with an ultra-sound probe (Vibra Cell 50 — sonics \& Materials Inc. Danbury, CT, USA) for 3×2 min on ice, and centrifuged at 10,000 rpm for $10 \mathrm{~min}$. The supernatant was collected and separated into two fractions. One fraction was filtrated with a $0.2 \mu \mathrm{m}$ pore filter and used directly for toxicity assessment. This fraction constituted the crude extract. The other fraction was fractionated by solid-phase extraction with Bond Elute C18 cartridges. Three fractions were prepared for each sample: one pigment fraction resulted from washing the cartridges with natural seawater (this fraction contains hydrophilic compounds such as pigments, salts and carbohydrates), a methanolic extract resulted from the passage of 50\% methanol (Methanolic I extract) and another methanolic extract resulted from washing the cartridges with 100\% methanol (Methanolic II extract). The methanolic fractions were evaporated to dryness so that all methanol was removed. Samples were resuspended in filtrated natural seawater. Extracts were stored at $-20{ }^{\circ} \mathrm{C}$ prior to the toxicity experiments.

\subsection{Toxicity assessment}

2.3.1. Acute toxicity assay using nauplii of the crustacean Artemia salina

Toxicity was screened using $24 \mathrm{~h} \mathrm{~A}$. salina nauplii freshly hatched from dried cysts (JBL Novotemia, Germany). Cysts were hatched in $35 \mathrm{~g} / \mathrm{l}$ natural seawater previously filtered through a $0.2 \mu \mathrm{m}$ pore filter 
and maintained at $25^{\circ} \mathrm{C}$ under conditions of continuous illumination and aeration. After $24 \mathrm{~h}$, A. salina nauplii were separated from egg shells and remaining cysts separated using a Pasteur pipette. Toxicity assays were performed in 96 micro-well polystyrene plates. Aliquots of nauplii solution containing 10-15 organisms were pipetted into each well containing $200 \mu \mathrm{l}$ of each cyanobacterial extract and, in the case of control trials, natural filtered seawater. The plates were covered with parafilm to prevent water loss and then incubated at $25{ }^{\circ} \mathrm{C}$, for $24 \mathrm{~h}$ in darkness. Plates were maintained in constant agitation, once if the solution is in permanent motion it is easier for the larvae to remain close to the surface, where the oxygen level is higher. After 24 and $48 \mathrm{~h}$, the number of dead larvae in each well was counted. Larvae were considered dead if they did not exhibit any internal or external movement over $30 \mathrm{~s}$ of observation. The total number of shrimps per well was determined after fixation with a lugol solution. Results were calculated as percentage mortality. All experiments were carried out in triplicate.

\subsubsection{Acute toxicity assay using the rotifer Brachionus plicatillis}

A commercially available toxicity assay was performed (ROTOXKIT M, Strategic Diagnostics Inc., USA). Briefly, rotifer cyst hatching was initiated $28 \mathrm{~h}$ prior to the start of the test in hatching medium provided by the kit. Cysts were maintained at $25{ }^{\circ} \mathrm{C}$ under continuous illumination. The bioassay was conducted in disposable PVC multiwell plates with a volume of $300 \mu$ per well. Six wells with five rotifers each were tested per extract. Incubation was done for $24 \mathrm{~h}$, at $25^{\circ} \mathrm{C}$ and in darkness. After the incubation time, the number of dead rotifers per extract was registered and the percentage of mortality calculated.

\subsubsection{Embryo-larval acute toxicity assay using the sea urchin Paracentrotus lividus}

Sea urchins were collected from rocky shores at S. Bartolomeu (Esposende, North Portugal) considered as a reference site for water quality, due to the low influence of significant sources of pollution (Cairrão et al., 2004). Bioassays were performed according to the methods described by Fernández and Beiras (2001). Briefly, individuals were dissected and sperm and eggs directly pipetted from the gonads. Eggs from an optimal condition female were collected in a $100 \mathrm{ml}$ measuring cylinder containing natural seawater filtered through a $0.2 \mu \mathrm{m}$ pore filter. A few microliters of undiluted sperm from one male were added to the egg suspension and carefully stirred to allow fertilization. Fertilization success and egg density were determined by counting the fertilized eggs in four $10 \mu$ l aliquots.

Fertilized eggs were exposed to the crude extracts and the partially purified extracts in 24 -well plates, for a 48 -h period and at $20{ }^{\circ} \mathrm{C}$. Test solutions consisted of $3 \mathrm{ml}$ of each cyanobacterial extract and $3 \mathrm{ml}$ of natural seawater filtered through a $0.2 \mu \mathrm{m}$ pore filter as control. To each well fertilized eggs were added to a concentration of $20 \mathrm{eggs} / \mathrm{ml}$ of solution. After incubation, the solutions were fixed with $40 \%$ formalin. Three replicates of each experimental treatment were done. Embryogenesis success was evaluated by measuring the percentage of pluteus larvae and the larval length. Differences in larval length in cyanobacterial extracts were compared to the control using the non-parametric Kolmogorov-Smirnov test for two independent samples, since data did not exhibit normality and homoscedasticity. Statistical treatments were performed by using the SPSS 11.5 statistical package. 


\subsubsection{Embryo-larval acute toxicity assay using the mussel Mytilus galloprovincialis}

The embryo-larval acute toxicity assay using M. galloprovincialis was performed with extracts of the Synechococcus sp. strain LEANCYA 16 and the Synechocystis sp. strain LEANCYA 21.

Mussels were obtained from a commercial hatchery in Vigo (Spain). The bioassay was based on the methods described by His et al. (1997). Briefly, animals were cleaned and scrubbed in natural filtered seawater. Spawning was induced by raising the temperature until $22{ }^{\circ} \mathrm{C}$. Freshly collected oocytes and sperm were suspended in a $100 \mathrm{ml}$ measuring cylinder containing natural seawater filtered through a $0.2 \mu \mathrm{m}$ pore filter to achieve fertilization, facilitated by gentle stirring. The density of fertilized eggs was assessed by counting the fertilized eggs in four $10 \mu \mathrm{l}$ aliquots. 30 min-old fertilized eggs were incubated in the test solutions at a concentration of $20 \mathrm{eggs} / \mathrm{ml}$. Incubation was conducted for $48 \mathrm{~h}$ at $20^{\circ} \mathrm{C}$ as described for the sea urchin test. Results were recorded as percentage of embryos that reached the D-larvae stage.

\section{Results}

\subsection{Acute toxicity assay using nauplii of the crustacean Artemia salina}

The results of the toxicity assessment of the four extracts of 12 cyanobacterial strains to the brine shrimp A. salina are summarized in Table 2. From this assay, the control trials registered a survival of $100 \%$. The same result was obtained for both incubation times and for all extracts of the Synechococcus strains LEANCYA 10 and 11 and the Synechocystis strain LEANCYA 13. For the strain LEANCYA 20, only a mortality of $19.5 \pm 2.8 \%$ was found for the crude extract and during an exposure period of $48 \mathrm{~h}$. In the experiment with the Synechococcus strain LEANCYA 7 and the Synechocystis LEANCYA 21, 100\% mortality was registered in the crude extract after $24 \mathrm{~h}$ exposure and no mortality was observed for the pigment and methanolic extracts after both 24 and 48 h exposure. The Synechococcus strains LEANCYA 16 and 19 displayed the most relevant toxic effects, with $100 \%$ mortality for the crude and the pigment extracts. In the methanolic fractions toxicity was found after $48 \mathrm{~h}$ of exposure, although in a much lower range. Following these strains, the strains LEANCYA 17 and 18 caused also 100\% mortality at the crude extract after $24 \mathrm{~h}$ exposure and also caused mortality at the methanolic extracts after $48 \mathrm{~h}$ incubation. 


\begin{tabular}{|c|c|c|c|c|c|c|c|c|}
\hline \multirow[t]{3}{*}{ Cyanobacteria } & \multicolumn{8}{|c|}{ Extract } \\
\hline & \multicolumn{2}{|c|}{ Crude } & \multicolumn{2}{|c|}{ Pigment } & \multicolumn{2}{|c|}{ Methanolic I } & \multicolumn{2}{|c|}{ Methanolic II } \\
\hline & $24 \mathrm{~h}$ & $48 \mathrm{~h}$ & $24 \mathrm{~h}$ & $48 \mathrm{~h}$ & $24 \mathrm{~h}$ & $48 \mathrm{~h}$ & $24 \mathrm{~h}$ & $48 \mathrm{~h}$ \\
\hline CONTROL & 0 & 0 & & & & & & \\
\hline LEANCYA 1 & 0 & $18.3 \pm 2.5$ & 0 & 0 & 0 & 0 & 0 & $12.2 \pm 5.3$ \\
\hline LEANCYA5 & 0 & $13.3 \pm 6.0$ & 0 & 0 & 0 & $8.8 \pm 1.2$ & 0 & 0 \\
\hline LEANCYA 7 & 100 & - & 0 & 0 & 0 & 0 & 0 & 0 \\
\hline LEANCYA 10 & 0 & 0 & 0 & 0 & 0 & 0 & 0 & 0 \\
\hline LEANCYA 11 & 0 & 0 & 0 & 0 & 0 & 0 & 0 & 0 \\
\hline LEANCYA 13 & 0 & 0 & 0 & 0 & 0 & 0 & 0 & 0 \\
\hline LEANCYA 16 & 100 & - & 100 & - & 0 & $16.1 \pm 5.2$ & 0 & $8.4 \pm 2.0$ \\
\hline LEANCYA 17 & 100 & - & 0 & 0 & 0 & $10.5 \pm 1.8$ & 0 & 0 \\
\hline LEANCYA 18 & 100 & - & 0 & 0 & 0 & $8.2 \pm 0.8$ & 0 & $4.4 \pm 4.9$ \\
\hline LEANCYA 19 & 100 & - & 100 & - & 0 & $12.4 \pm 4.2$ & 0 & 0 \\
\hline LEANCYA 20 & 0 & $19.5 \pm 2.8$ & 0 & 0 & 0 & 0 & 0 & 0 \\
\hline LEANCYA21 & 100 & - & 0 & 0 & 0 & 0 & 0 & 0 \\
\hline
\end{tabular}

Data are expressed in percentage mortality \pm standard deviation.

\subsection{Acute toxicity assay using the rotifer Brachionus plicatillis}

For the rotifer assay, 100\% survival was recorded for all strains and extracts except for Synechococcus sp. strain LEANCYA 19. In this case, $20.9 \pm 5.5 \%$ of mortality was registered for the crude extract. Control registered $100 \%$ survival after the $24 \mathrm{~h}$ incubation time.

3.3. Embryo-larval acute toxicity assay using the sea urchin Paracentrotus lividus

Table 3 summarizes the results of the embryogenesis development of fertilized eggs for the control and the groups exposed to the four cyanobacterial extracts. After $48 \mathrm{~h}$ of incubation, $96.7 \pm 1.5 \%$ of $P$. lividus fertilized eggs from the control developed into normal pluteus larvae ( Fig. 2a) with an average length of $503.00 \pm 29.20 \mu \mathrm{m}$. When $P$. lividus fertilized eggs were exposed to the cyanobacterial extracts, negative effects were detected with inhibition of embryonic development ( Fig. 2b and c), and development of smaller pluteus larvae ( Fig. 1). 
Table 3 .

Toxicity of the crude extract, pigment extract, methanolic I and methanolic II extract of ten cyanobacterial strains to the embryos of the sea-urchin Paracentrotus lividus

\begin{tabular}{|c|c|c|c|c|c|c|c|c|}
\hline \multirow[t]{3}{*}{ Cyanobacterial strain } & \multicolumn{8}{|l|}{ Extract } \\
\hline & \multicolumn{2}{|l|}{ Crude } & \multicolumn{2}{|l|}{ Pigment } & \multicolumn{2}{|c|}{ Methanolic I } & \multicolumn{2}{|c|}{ Methanolic II } \\
\hline & $\%$ & Stage & $\%$ & Stage & $\%$ & Stage & $\%$ & Stage \\
\hline Control & $96.7 \pm 1.5$ & $\mathrm{PI}$ & & & & & & \\
\hline LEANCYA 1 & 0 & M & 0 & $\mathrm{M}, \mathrm{G}$ & 0 & $\mathrm{M}, \mathrm{G}$ & 0 & $\mathrm{Pr}$ \\
\hline LEANCYA5 & 0 & $\mathrm{M}$ & $91.7 \pm 1.5$ & PI & 0 & $\mathrm{M}$ & $90.0 \pm 2.0$ & $\mathrm{PI}$ \\
\hline LEANCYA 7 & 0 & M & 87 & PI & 0 & $\mathrm{M}$ & 0 & Pr \\
\hline LEANCYA 11 & 0 & $\mathrm{M}$ & 0 & $\mathrm{Pr}$ & 0 & $\mathrm{M}$ & $77.7 \pm 2.1$ & $\mathrm{PI}$ \\
\hline LEANCYA 16 & 0 & M & 0 & $\mathrm{G}, \mathrm{Pr}$ & 0 & $B, G$ & 0 & $\mathrm{~F}$ \\
\hline LEANCYA 17 & 0 & $\mathrm{M}$ & $93.7 \pm 2.9$ & $\mathrm{PI}$ & 0 & M & 0 & $\mathrm{Pr}$ \\
\hline LEANCYA 18 & 0 & $E$ & 0 & $\mathrm{E}$ & 0 & $M, G$ & 0 & $\mathrm{Pr}$ \\
\hline LEANCYA 19 & 0 & $\mathrm{M}$ & 0 & $\mathrm{M}$ & 0 & $\mathrm{M}$ & 0 & $M$ \\
\hline LEANCYA 20 & 0 & $B$ & 0 & G & 0 & $\mathrm{Pr}$ & $92.0 \pm 2.6$ & $\mathrm{PI}$ \\
\hline LEANCYA 21 & 0 & - & 0 & $\mathrm{Pr}$ & 0 & $\mathrm{Pr}$ & 0 & $\mathrm{Pr}$ \\
\hline
\end{tabular}

Results are expressed in percentage of embryological success \pm standard deviation and reached stage (F - fertilized eggs; E disintegrated embryos; M-morula; B - blastula; G-gastrula; $\mathrm{Pr}$ - prisma or prepluteus larva; PI-pluteus larva).

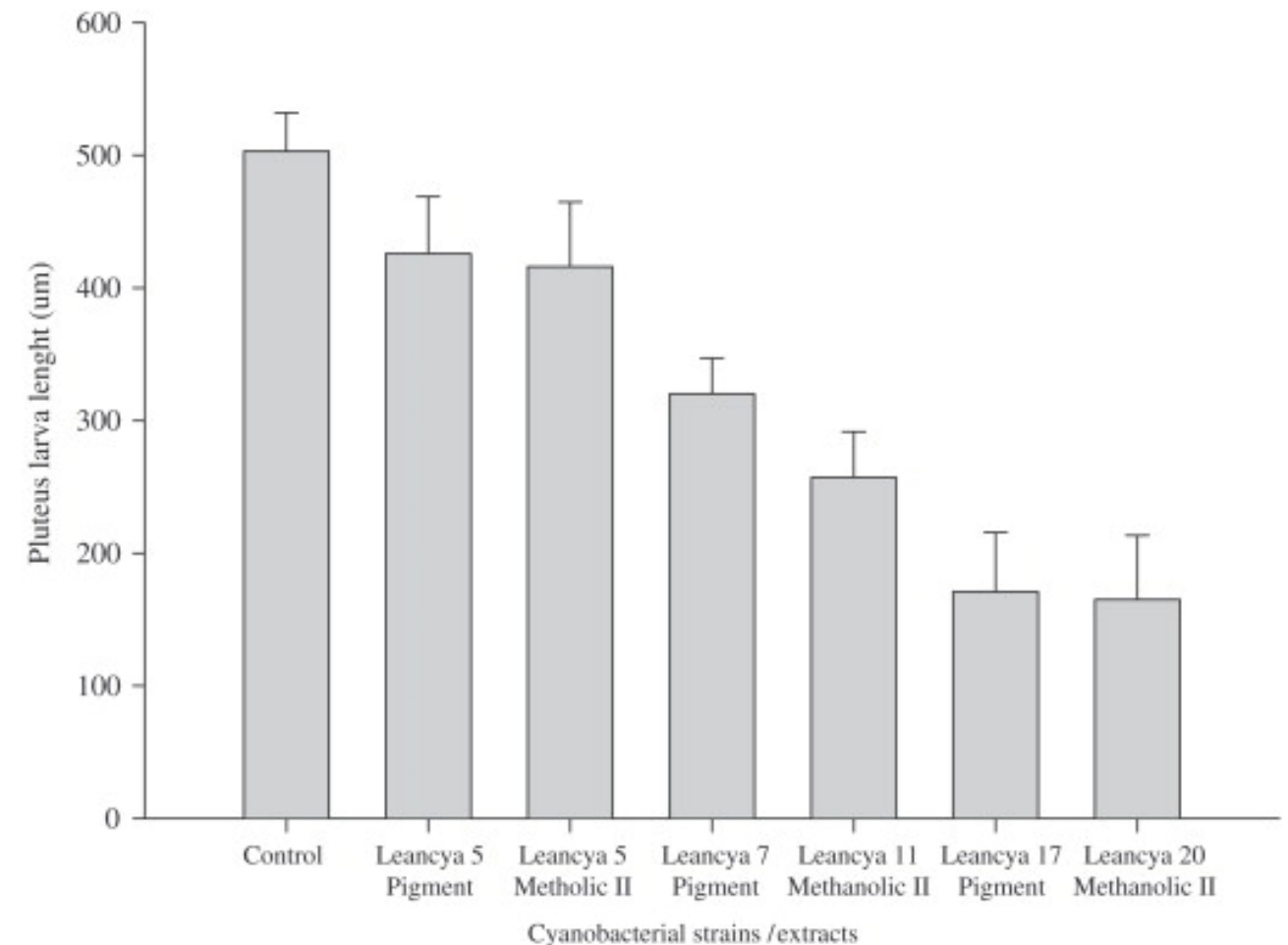

Fig. 1.

Pluteus larvae length of sea urchin larvae that developed from embryos incubated in natural filtered seawater (control) and marine cyanobacterial extracts (strains LEANCYA 5, 7, 11, 17 and 20). Values represent the meantstandard deviation from three replicates. Significant difference on larval length respective to the control $(\rho<0.05)$ were observed for all larvae exposed to the cyanobacterial extracts. 

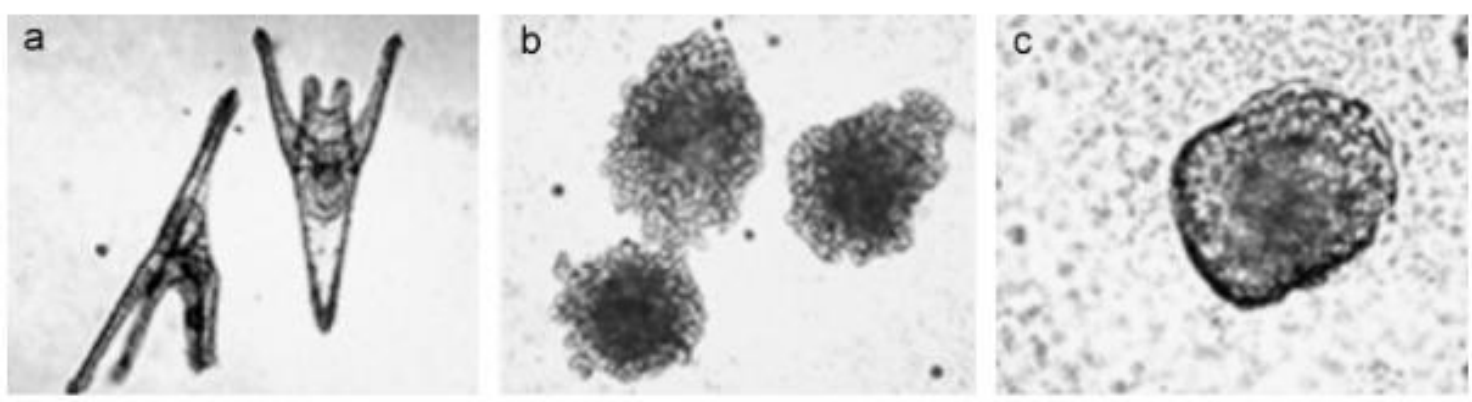

Fig. 2 .

Effects of marine cyanobacterial extracts on embryogenesis of the sea urchin Paracentrotus Iividus. (a) Normal pluteus larvae resulting from control treatment; (b and c) abnormally developed embryos resulting from treatments with cyanobacterial extracts.

Toxicity assays with crude and methanolic I extracts displayed an evident toxic effect by completely inhibiting embryogenesis, with most of the embryos reaching only the morula stage (Table 3). The pigment and methanolic II extracts showed inhibition of embryogenesis by almost all cyanobacterial strains, although the inhibition occurred at higher stages, such as the gastrula stage and the prepluteus larvae stages. However, for some of the strains, no apparent embryotoxicity was caused by the pigment extract (strains LEANCYA 5, 7, 17) and methanolic II extract (strains LEANCYA 5, 11, 20), with embryos developing into normal pluteus larvae. Nevertheless, statistically significant differences were found in larvae length when compared to the control (Fig. 1). Differences in length ranged from 33\% (LEANCYA 20 methanolic II extract) to $85 \%$ (LEANCYA 5 pigment extract).

\subsection{Embryo-larval acute toxicity assay using the mussel Mytilus galloprovincialis}

Normal D-larvae were obtained in the control assay with natural filtrated seawater (Fig. 3a). Nevertheless, inhibition of the embryonic development was observed (Fig. 3b and c) when fertilized eggs were exposed to the cyanobacterial extracts, with no obvious toxicity pattern between the Synechocystis and Synechococcus cyanobacterial strains tested.
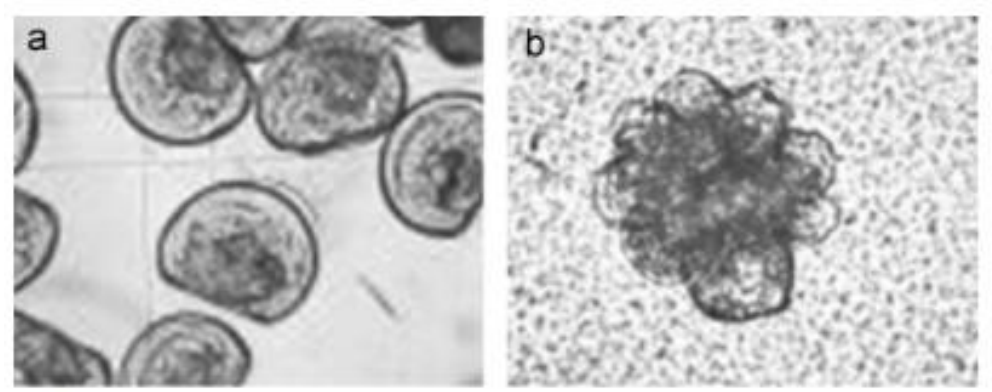

\section{C}

Fig. 3.

Effects of marine cyanobacterial extracts on embryogenesis of the mussel Mytilus galloprovincial/s. (a) Normal D-larvae resulting from the control treatment; (b and c) abnormally developed embryos resulting from treatments with cyanobacterial extracts.

\section{Discussion}


The results of the present study revealed the ability of marine Synechocystis and Synechococcus crude and partially purified extracts to be toxigenic to early life stages of marine invertebrates. To our knowledge, this is the first study on the toxicity of Synechocystis and Synechococcus strains from marine environments to marine invertebrates.

According to the results obtained in the assay using A. salina, both Synechocystis and Synechococcus strains displayed a negative effect on the survival of the nauplii. Crude extracts of half of the tested strains revealed an evident toxic effect by causing $100 \%$ mortality after $24 \mathrm{~h}$ of exposure. The strains that caused mortality at the crude extract caused also mortality at the pigment fraction (Synechocystis sp. strain LEANCYA 21), at the methanolic fractions (strains LEANCYA 1, 5, 17, 18, 19) or in all fractions (Synechococcus sp. strain LEANCYA 16). We may therefore infer that chemically different toxic compounds are produced and these are both of hydrophilic and hydrophobic nature. The highest toxic effects registered for the crude extracts could be the result of a mixture of different compounds that together may exercise a synergistic toxic effect. Maximum sensitivity to methanolic extracts was reached after $48 \mathrm{~h}$ exposure. This is in accordance with several studies that found that artemia greatest sensitivity to test compounds is reached at or after $48 \mathrm{~h}$ incubation ( Sánches-Fortún et al., 1996; Caldwell et al., 2003).

According to the assay using the rotifer B. plicatillis, our results showed that the tested cyanobacterial stains did not display acute toxicity to this rotifer species. Several authors reported a lower sensitivity of rotifers to cyanobacterial toxins when compared to other organisms ( Maršálek and Bláha, 2004). Gilbert (1990) interpreted the low sensitivity of the rotifer to cyanobacterial compounds as a general property of this taxonomic group since it is also considered a resistant group to toxicants other than cyanobacterial toxins ( Snell and Janssen, 1995). Despite the non-toxic effects or the slight toxic effects registered (LEANCYA 19 , crude extract), there is the possibility of these organisms to accumulate toxins and transfer it through the food web since it is reported that aquatic organisms, namely zooplankton, can accumulate cyanotoxins and transfer it to higher food chain levels ( Engstrom-Ost et al., 2002; Ferrão-Filho et al., 2002).

The toxic effect of the different extracts of the cyanobacterial strains was evident for the embryos of the sea urchin P. lividus and the mussel M. galloprovincialis. In most of the cases, embryogenesis cessed at the first stages of development which provide a strong evidence for the presence of compounds which interfere with growth factors on cells. Compounds interfering with growth factors have been previously found in cyanobacteria ( Poncet, 1999; Da Rocha et al, 2001) and marine algae ( Pesando et al., 1996). Compounds isolated from marine algae and dinoflagellates were also found to cause toxic effects on cleavage and embryonic development at the first steps of embryogenesis in sea urchin embryos ( Pesando et al., 1996; Sellem et al., 2000).

For some strains and extracts, embryogenesis of the sea urchin embryos was not inhibited but the resulting larvae were significantly smaller than larvae from the control treatment (Fig. 1). In these cases, the developmental defects were provoked without affecting the embryos development. These effects could be 
a result of compounds that are present in low concentrations as it was reported by Sellem et al. (2000), when they tested the effects of different concentrations of unsaturated fatty acids of a dinoflagellate species to embryos of the sea urchin $P$. lividus. There is also the possibly of occurrence of cytogenetic damages, as it was demonstrated by Hagger et al. (2005) to the mussel Mytilus edulis exposed to tritiated water. These authors considered that induced damages at lower levels of biological organization could manifest later during the developmental process.

In spite of the low number of cyanobacterial strains tested for toxicity to M. galloprovincialis embryos, toxic effects were evident. All cyanobacterial extracts inhibited embryogenesis at the early development stages of the mussel embryos with no toxicity pattern between strains. From the results, no difference in sensitivity can be drawn between embryos of the sea urchin and the mussels. This is in accordance with reports comparing the toxicity of chemicals such as heavy metals and pesticides to the embryogenesis success of mussels and sea urchins, where no specific toxicity pattern between the two organisms is given ( His et al., 1999).

It was an overall finding that cyanobacterial crude extracts caused stronger effects than partially purified extracts. These results support the production of different toxic compounds with different chemical natures and with a possible synergistic effect. Several compounds of the crude extract, along with compounds of the pigment extract, are soluble in water. This hydrophilic nature highlights its potential toxic action by the fact that they are immediately available in water after cell lyses.

Although the results of the present study are only based in acute toxicity assays, the effects of the cyanobacteria in marine invertebrates confirm the potential threat that these organisms can pose to the ecosystems. The production of toxic metabolites could represent an ecological risk for embryos and larvae of marine organisms that are in contact with cyanobacteria and therefore constitute a threat to the ecosystem health. The impact of these cyanobacterial strains on marine invertebrates needs however further investigations to elucidate the potential long-term damage induced by persistent contact with cyanobacteria.

\section{References}

Albert et al., 2005 S. Albert, J.M. O’Neil, J.W. Udy, S. Ahern, C.M. O'Sullivan, W.C. Dennison Blooms of the cyanobacterium Lyngbya majuscula in coastal Queensland, Australia: disparate sites, common factors Mar. Pollut. Bull., 51 (2005), pp. 428-437

Beiras et al., 2003 R. Beiras, J. Bellas, N.E.M. Fernández, A. Cobelo-García Assessment of coastal marine pollution in Galicia (NW Iberian Peninsula); metal concentration in seawater, sediments and mussels (Mytilus galloprovincialis) versus embryo-larval bioassays using Paracentrotus lividus and Ciona intestinalis Mar. Environ. Res., 56 (2003), pp. 531-553 
Cairrão et al., 2004 E. Cairrão, M. Couderchet, A.M.V.M. Soares, L. Guilhermino Glutathione-Stransferase activity of Fucus spp. as a biomarker of environmental contamination Aquat. Toxicol., 70 (2004), pp. 277-286

Caldwell et al., 2003 G.S. Caldwell, M.G. Bentley, P.J.W. Olive The use of the brine shrimp (Artemia salina) bioassay to assess the toxicity of diatom extracts and short chain aldehydes Toxicon, 42 (2003), pp. 301-306

Campbell et al., 1994 D.L. Campbell, L.A. Lawton, K.A. Beattie, G.A. Codd Comparative assessment of the specificity of the brine shrimp and microtox assays to hepatotoxic (microcystin-LR-containing cyanobacteria Environ. Toxicol. Water Qual., 9 (1994), pp. 71-77

Carpenter et al., 2004 E.J. Carpenter, A. Subramaniam, D.G. Capone Biomass and primary productivity of the cyanobacterium Trichodesmium spp. in the tropical N Atlantic Ocean DeepSea Res. I, 51 (2004), pp. 173-203

Codd et al., 2005 G.A. Codd, L.F. Morrison, J.S. Metcalf Cyanobacterial toxin: risk management for health protection Toxicol. Appl. Pharmacol., 203 (3) (2005), pp. 264-272

Da Rocha et al., 2001 A.B. Da Rocha, R. Lopes, G. Schwartsmann Natural products in anticancer therapy Curr. Opin. Pharmacol., 1 (2001), pp. 364-369

Engstrom-Ost et al., 2002 J. Engstrom-Ost, M. Lehtiniemi, S. Green, B. Kozlowsky-Suzuki, M. Viitasalo Does cyanobacterial toxin accumulate in mysid shrimp and fish via copepods? J. Exp. Mar. Biol. Ecol., 276 (1-2) (2002), pp. 95-107

Fernández and Beiras, 2001 N. Fernández, R. Beiras Combined toxicity of dissolved mercury with copper, lead and cadmium on embryogenesis and early larval growth of the Paracentrotus lividus sea-urchin Ecotoxicology, 10 (5) (2001), pp. 263-271

Ferrão-Filho et al., 2002 A.S. Ferrão-Filho, B. Kozlowsky-Suzuki, S.M.F.O. Azevedo Acumulation of microcystins by a tropical zooplankton community Aquat. Toxicol., 59 (3-4) (2002), pp. 201208

Gerwick et al., 1994 W.H. Gerwick, P.J. Proteau, D.G. Nagle, E. Hamel, A. Blokhin, D.L. Slate Structure of curacin A, a novel antimitotic, antiproliferative and brine shrimp toxic natural product from the marine cyanobacterium Lyngbya majuscule J. Org. Chem., 59 (1994), pp. 12431245

Gilbert, 1990 J.J. Gilbert Differential effects of Anabaena affinis on cladocerans and rotifers: mechanisms and implications Ecology, 71 (5) (1990), pp. 1727-1740

Graber and Gerwick, 1998 M.A. Graber, W.H. Gerwick Kalkipyrone, a toxic g-pyrone from an assemblage of the marine cyanobacteria Lyngbya majuscula and Tolypothrix sp J. Nat. Prod., 61 (1998), pp. 677-680

Hagger et al., 2005 J.A. Hagger, F.A. Atienzar, A.N. Jha Genotoxic, cytotoxic, developmental and survival effects of tritiated water in the early life stages of the marine mollusc, Mytilus edulis Aquat. Toxicol., 74 (3) (2005), pp. 205-217

Hawser et al., 1992 S.P. Hawser, J.M. O'Neil, M.R. Roman, G.A. Codd Toxicity of blooms of the cyanobacterium Trichodesmium to zooplankton J. Appl. Phycol., 4 (1992), pp. 79-86 
His et al., 1997 E. His, M.N.L. Seaman, R. Beiras A simplification the bivalve embryogenesis and larval development bioassay method for the water quality assessment Water Res., 31 (2) (1997), pp. 351-355

His et al., 1999 E. His, I. Heyvang, O. Gefard, X. Montaudouin A comparison between oyster (Crassostrea gigas) and sea urchin (Paracentrotus lividus) larval bioassays for toxicological studies Water Res., 33 (7) (1999), pp. 1706-1718

Kiviranta et al., 1991 J. Kiviranta, K. Sivonen, S.I. Niemela Detection of toxicity of cyanobacteria by Artemia salina bioassay Environ. Toxicol. Water Qual., 6 (1991), pp. 423-436

Kotai, 1972 Kotai, J., 1972. Instructions for Preparation of Modified Nutrient Solution Z8 for Algae. Norwegian Institute for Water Research, Blindern, Oslo, p. 5.

Maršálek and Bláha, 2004 B. Maršálek, L. Bláha Comparison of 17 biotests for detection of cyanobacterial toxicity Environ. Toxicol., 19 (2004), pp. 310-317

Martin et al., 1981 M. Martin, K.E. Osborn, P. Billig, N. Glickstein Toxicities of ten metals to Crassostrea gigas and Mytilus edulis embryos and Cancer magister larvae Mar. Pollut. Bull., 12 (1981), pp. 304-308

Negri et al., 2004 A.P. Negri, O. Bunter, B. Jones, L. Llewellyn Effects of the bloom-forming alga Trichodesmium erythraeum on the pearl oyster Pinctada maxima Aquaculture, 232 (2004), pp. 91-102

Orjala and Gerwick, 1996 J. Orjala, W.H. Gerwick Barbamide, a chlorinated metabolite with molluscicidal activity from the Caribbean cyanobacterium Lyngbya majuscule J. Natl. Prod., 59 (1996), pp. 427-430

Osborne et al., 2001 N.J.T. Osborne, P.M. Webb, G.R. Shaw The toxins of Lyngbya majuscula and their human and ecological health effects Environ. Int., 27 (5) (2001), pp. 381-392

Pesando, 1996 D. Pesando, R. Lemée, C. Ferrua, P. Amade, J.P. Girard Toxic effects of caulerpenyne extracted from Caulerpa taxifolia on mechanisms related to sea urchin egg cleavage Aquat. Toxicol., 35 (1996), pp. 139-155

Pittman and Pittman, 2005 S.J. Pittman, K.M. Pittman Short-term consequences of a benthic cyanobacterial bloom (Lyngbya majuscula Gomont) for fish and penaeid prawns in Moreton Bay (Queensland, Australia) Estuar. Coast. Shelf Sci., 63 (2005), pp. 619-632

Poncet, 1999 J. Poncet The dolastatins, a family of promising antineoplastic agents Curr. Pharmaceut. Des., 5 (1999), pp. 139-162

Pushparaj et al., 1999 B. Pushparaj, E. Pelosi, F. Jüttner Toxicological analysis of the marine cyanobacterium Nodularia harveyana J. Appl. Phycol., 10 (1999), pp. 527-530

Rantajärvi, 1998 Rantajärvi, E., 1998. Phytoplankton blooms in the Finnish sea areas and in the Baltic Proper during 1997. Report Series of the Finnish Institute of Marine Research 36.

Repka et al., 2004 S. Repka, M. Meyerhöfer, K. von Bröckel, K. Sivonen Associations of cyanobacterial toxin, nodularin, with environmental factors and zooplankton in the Baltic Sea Microb. Ecol., 47 (2004), pp. 350-358 
Sánches-Fortún et al., 1996 S. Sánches-Fortún, S. Sanz, M.V. Barahona Acute toxicity of several organophosphorous insecticides and protection by cholinergic antagonist and 2-PAM on Artemia salina larvae Arch. Environ. Contam. Toxicol., 31 (1996), pp. 391-398

Sellem et al., 2000 F. Sellem, D. Pesando, G. Bodennec, A.E. Abed, J.P. Girard Toxic effects of Gymnodinium CF. mikimotoi unsaturated fatty acids to gametes and embryos of the sea urchin Paracentrotus lividus Water Res., 34 (2) (2000), pp. 550-556

Sivonen et al., 1989 K. Sivonen, K. Kononen, W.W. Carmichael, A.M. Dahlem, K. Rinehart, J. Kiviranta, S.I. Niemelä Occurrence of the hepatotoxic cyanobacterium Nodularia spumigena in the Baltic Sea and the structure of the toxin Appl. Environ. Microbiol., 55 (8) (1989), pp. 19901995

Smith, 1996 P.T. Smith Toxic effects of blooms of marine species of Oscillatoriales on farmed prawns (Penaeus monodon, Penaeus japonicus) and brine shrimp (Artemia salina) Toxicon, 34 (8) (1996), pp. 857-869

Snell and Janssen, 1995 T.W. Snell, C.R. Janssen Rotifers in ecotoxicology: a review Hydrobiologia, 313/314 (1995), pp. 231-247

Solis et al., 1993 P.N. Solis, C.W. Wright, M.M. Anderson, M.P. Gupta, J.D. Phillipson A microwell cytotoxicity assay using Artemia salina Planta Med., 59 (1993), pp. 250-252

Watkinson et al., 2005 A.J. Watkinson, J.M. O'Neil, W.C. Dennison Ecophysiology of the marine cyanobacterium, Lyngbya majuscula (Oscillatoriaceae) in Moreton Bay, Australia Harmful Algae, 4 (2005), pp. 697-715

Wiegand and Pflugmacher, 2005 C. Wiegand, S. Pflugmacher Ecotoxicological effects of selected cyanobacterial secondary metabolites a short review Toxicol. Appl. Pharmacol., 203 (3) (2005), pp. 201-218 